\title{
Personal use of permanent hair dyes and cancer risk and mortality in US women: prospective cohort study
}

\author{
Yin Zhang, ${ }^{1,2,3}$ Brenda M Birmann, ${ }^{1}$ Jiali Han, ${ }^{1,4,5}$ Edward L Giovannucci, ${ }^{1,3,6}$ Frank E Speizer, ${ }^{1,7}$ \\ Meir J Stampfer, ${ }^{1,3,6}$ Bernard A Rosner, ${ }^{1,8}$ Eva S Schernhammer ${ }^{1,3,9}$
}

For numbered affiliations see end of the article.

Correspondence to:

E S Schernhammer,

Channing Division of Network

Medicine, Department of

Medicine, Brigham and Women's

Hospital and Harvard Medical

School, Boston, MA 02115, USA

eva.schernhammer@channing.

harvard.edu

(ORCID 0000-0002-4337-9415)

Additional material is published

online only. To view please visit

the journal online.

Cite this as: $B M / 2020 ; 370: \mathrm{m} 2942$

http://dx.doi.org/10.1136/bmj.m2942

Accepted: 4 July 2020

\section{ABSTRACT}

OBJECTIVE

To evaluate the associations between personal use of permanent hair dyes and cancer risk and mortality.

DESIGN

Prospective cohort study.

\section{SETTING AND PARTICIPANTS}

117200 women enrolled in the Nurses' Health Study, an ongoing prospective cohort study of female nurses in the United States. The women were free of cancer at baseline, reported information on personal use of permanent hair dyes, and were followed for 36 years.

\section{EXPOSURE}

Status, duration, frequency, and integral use (cumulative dose calculated from duration and frequency) of permanent hair dyes. Age at first use and time since first use of permanent hair dyes.

\section{MAIN OUTCOME MEASURES}

Associations of personal use of permanent hair dyes with risk of overall cancer and specific cancers, and cancer related death. Age and multivariable adjusted hazard ratios and $95 \%$ confidence intervals were estimated by using Cox proportional hazard models.

RESULTS

Ever users of permanent hair dyes had no significant increases in risk of solid cancers $(n=20805$, excluding non-melanoma skin cancers; hazard ratio $0.98,95 \%$ confidence interval 0.96 to 1.01 ) or hematopoietic cancers overall $(n=1807 ; 1.00,0.91$ to 1.10) compared with non-users. Additionally, ever users did not have an increased risk of most specific cancers (cutaneous squamous cell carcinoma, bladder

\section{WHAT IS ALREADY KNOWN ON THIS TOPIC}

The International Agency for Research on Cancer classified occupational exposure to hair dyes as a probable carcinogen to humans (group $2 A$ ), whereas personal use of hair dyes was not classifiable (group 3)

Current epidemiological evidence remains inconclusive, therefore concern exists about the carcinogenic potential of personal use of permanent hair dye, which is the most aggressive type and the most extensively used

\section{WHAT THIS STUDY ADDS}

In this large prospective study, no positive association was found between personal use of permanent hair dye and risk of most cancers or cancer related mortality

Positive associations were observed for risk of basal cell carcinoma, breast cancer (estrogen receptor negative, progesterone receptor negative, hormone receptor negative), and ovarian cancer

An increased risk of Hodgkin lymphoma was observed among women with naturally dark hair, and a higher risk of basal cell carcinoma was found among women with naturally light hair cancer, melanoma, estrogen receptor positive breast cancer, progesterone receptor positive breast cancer, hormone receptor positive breast cancer, brain cancer, colorectal cancer, kidney cancer, lung cancer, and most of the major subclasses and histological subtypes of hematopoietic cancer) or cancer related death ( $n=4860 ; 0.96,0.91$ to 1.02$)$. Basal cell carcinoma risk was slightly increased for ever users ( $n=22560 ; 1.05,1.02$ to 1.08). Cumulative dose was positively associated with risk of estrogen receptor negative breast cancer, progesterone receptor negative breast cancer, hormone receptor negative breast cancer, and ovarian cancer. An increased risk of Hodgkin lymphoma was observed only for women with naturally dark hair (based on 70 women, 24 with dark hair), and a higher risk of basal cell carcinoma was observed for women with naturally light hair.

\section{CONCLUSION}

No positive association was found between personal use of permanent hair dye and risk of most cancers and cancer related mortality. The increased risk of basal cell carcinoma, breast cancer (estrogen receptor negative, progesterone receptor negative, hormone receptor negative) and ovarian cancer, and the mixed findings in analyses stratified by natural hair color warrant further investigation.

\section{Introduction}

Use of hair dyes is prevalent in modern societies. ${ }^{12}$ In the United States and Europe, an estimated $50-80 \%$ of women and $10 \%$ of men aged 40 and older use hair dye, ${ }^{12}$ and the prevalence of hair dye use has remained stable over the past decades. ${ }^{13}$ The World Health Organization's International Agency for Research on Cancer and the US Food and Drug Administration have continuously monitored data on hair dye safety. ${ }^{13-5}$ Based on existing epidemiological evidence, animal bioassays, and mechanistic and other relevant data, the International Agency for Research on Cancer classified occupational exposure to hair dyes as a probable carcinogen (group 2A); however, the carcinogenicity resulting from personal use of hair dyes was not classifiable (group 3 ). ${ }^{1}$ Nonetheless, public concern remains about the carcinogenic potential of hair dyes. ${ }^{12467}$

Modern hair dyes include oxidative (permanent) dye, direct (semi-permanent or temporary) dye, and natural dye..$^{1-3} 7$ Among modern hair dyes, permanent hair dye has a market share of approximately $80 \%$ in the US and Europe, and even higher in Asia, ${ }^{13}$ and is the most aggressive and extensively used type that has posed the greatest potential concern. ${ }^{1-4} 7$ Permanent hair dye products typically consist of intermediates (para substituted aromatic amines) and couplers (meta 
substituted aromatic amines and other compounds), ${ }^{17}$ which can form pigment molecules through chemical reactions in the presence of oxidants. ${ }^{17}$ Personal use of permanent hair dyes results in dermal (the main route) and airborne routes of exposure to hair dye chemicals, ${ }^{17}$ and exposure to intermediates and couplers is much higher than that to the reaction product during the dyeing process. ${ }^{1}$ The National Toxicology Program led by US government agencies has classified some chemicals that are or were used in hair dyes as reasonably anticipated to be human carcinogens. ${ }^{8}$

Monitoring the carcinogenic hazard to people from personal use of permanent hair dyes has major public health implications. ${ }^{1-5} 79$ However, owing to the limitations of published epidemiological studies,

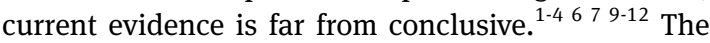
Nurses' Health Study ${ }^{13-16}$ has detailed assessments of permanent hair dye exposure ${ }^{17} 18$ and validated data on a wide spectrum of potential confounders and cancer outcomes. ${ }^{19-24}$ The study adds high quality human evidence to this field by performing a large prospective cohort study with over 117000 eligible participants and a 36 year follow-up.

\section{Methods}

\section{Study population}

Details of the Nurses' Health Study cohort have been described elsewhere. ${ }^{13-16}$ The study is an ongoing large prospective cohort study that started in 1976 and has enrolled 121700 US female nurses aged 3055 years. Self-administered questionnaires were sent to participants every two or four years (for diet related questions), and a response rate exceeding 90\% was achieved for most follow-up cycles. The study protocol was approved by the institutional review board of the Brigham and Women's Hospital (Boston, MA), and those of participating registries as required. Informed consent from participants was implied when they completed and returned the questionnaires. We used 1976 as the baseline, which was when exposure was first assessed. We excluded participants who reported no information on exposure at all assessments, those with a diagnosis of any cancer at baseline, and those who had missing information on age. Our analysis consisted of 117200 eligible participants.

\section{Personal use of permanent hair dyes}

The participants reported personal use of permanent hair dyes at baseline (1976), which included current or past use and duration, frequency, and age at first use, with updates every two years. ${ }^{17} 18$ Specifically, on the 1976 questionnaire, the participants reported whether they "had ever used a permanent hair dye (yes or no)," and whether they "have used permanent hair dyes for how many years (in years)." Participants were also asked "At what age did you first use a permanent hair dye? (in years of age)" in the same questionnaire. Additionally, in 1978, 1980, and 1982, the participants provided updated information on permanent hair dye use through questionnaires by answering the question "Do you use a permanent hair dye currently? (yes or no, not including temporary rinses)" and "How often do you currently use permanent hair dyes? (in every how many weeks)." Participants who reported ever use of permanent hair dyes in any of the assessments were classified as ever users, and all others as nonusers. Duration of use was calculated using baseline and cumulatively updated assessments of lifetime hair dye use history. Frequency of use was calculated as the average reported at baseline and during regular updates thereafter. Time since first use was determined according to responses and age. To assess an integrated measure of cumulative dose of permanent hair dye use, we multiplied the average frequency of use (times per year) by duration of use (years).

\section{Cancers and cancer related deaths}

Physician diagnosed incident invasive (with the exception of non-melanoma skin carcinoma) cancers were self-reported every two years on the questionnaires and confirmed by review of medical records and pathology reports (obtained with permission) or by linkage to state cancer registries. More than $96 \%$ of deaths were confirmed through next of kin or postal authority reporting, and regular searches of the National Death Index. ${ }^{2526}$ Investigators reviewed death certificates and medical records to classify the cause of death according to the international classification of diseases (eighth revision).

\section{Covariates}

We considered age, race, natural hair color, cumulative average body mass index, body mass index at age 18, smoking status, pack years of smoking, and alcohol intake as common confounders in analyses of all cancers. For more complete control of confounding, we also controlled for the following endpoint specific covariates in multivariable analyses of individual cancers and cancer death: physical activity, intake of total calories, total fluid, red or processed meat, fiber, folate, calcium and vitamin D, regular use of aspirin, non-aspirin nonsteroidal anti-inflammatory drugs, use of multivitamins, postmenopausal hormones and oral contraceptives, menopausal status, adolescent body size, age at menarche and first birth, parity, history of breastfeeding, current mammography use, screening colonoscopy or sigmoidoscopy in the previous two years, childhood reaction to sun, lifetime blistering sunburns, number of moles on arms, cumulative ultraviolet flux since baseline, ${ }^{27} 28$ history of hypertension, hypercholesterolemia, diabetes mellitus and breast disease, and family history of colorectal cancer and breast cancer. The validity and reproducibility of these covariates have been described previously. ${ }^{19}$ 20-24 The table and supplementary table footnotes list all the covariates in the corresponding models.

Metabolic equivalent of task (MET) scores were assigned to each reported type of common recreational activity, and total physical activity was calculated in MET hours per week. Information on the potential confounding variables was updated throughout follow- 
up, except for race, natural hair color, body mass index at age 18, age at menarche, age at first birth, history of breastfeeding, childhood reaction to sun, lifetime blistering sunburns and number of moles on arms. These variables were assessed once and assumed to remain mostly stable over time.

\section{Statistical analysis}

We calculated person years of follow-up from the date of return of the baseline questionnaire in 1976 until the date of any cancer diagnosis, death, loss to followup, or follow-up completion (30 June 2012), whichever was earliest. Age and multivariable adjusted hazard ratios and 95\% confidence intervals for outcomes were estimated by using Cox proportional hazard regression models conditioning on age (in months) and questionnaire cycle for each category of a given personal permanent hair dye use characteristic: overall status of use (non-user, ever user); duration of use (non-user, $<5$ years, 5-9 years, $\geq 10$ years); frequency of use (non-user, every $\geq 5$ weeks, every 1-4 weeks); cumulative dose (non-user, 1-99 times, 100-199 times, $\geq 200$ times); age at first use (non-user, $<30$ years, $\geq 30$ years); and time since first use (non-user, <30 years, $\geq 30$ years). We calculated $P$ value for trend by using the mid-point values of the following categories: duration and frequency of use, cumulative dose, age at first use, and time since first use. Women who never used permanent hair dyes served as the reference group in most of the analyses, except for analyses of age at first use and time since first use.

To further investigate cumulative dose dependent associations between personal use of permanent hair dye and outcomes, we estimated hazard ratios and 95\% confidence intervals for each 50 time increment in analyses among ever users, where the $\mathrm{P}$ value for trend was calculated by using the cumulative dose in times as a continuous variable. Dose-response relations were examined by using restricted cubic spline analysis. Tests for linear trend were performed by treating doses as continuous variables in models. We modeled exposures and all time varying covariates as time varying variables. Different sets of covariates were used for each type of cancer. We updated time varying covariates throughout follow-up to leverage the data updated every two years or every four years (for diet related data). To minimize missing information, when values were missing for variables that were repeatedly measured, we carried forward the values once from the most recent follow-up cycle. Additionally, we created missing indicators when necessary and included them in the models for the remaining covariates with missing values, an approach which has been applied in other studies using data from the Nurses' Health Study. ${ }^{29-33}$

The outcomes included incident overall cancers and individual cancers, and cancer related deaths. We performed analyses for specific solid cancers, including basal cell carcinoma, cutaneous squamous cell carcinoma, bladder cancer, breast cancer (stratified by hormone receptor status: estrogen receptor and progesterone receptor), brain cancer, melanoma, colorectal cancer, ovarian cancer, kidney cancer, and lung cancer. Separate analyses were also conducted for major subclasses and histological subtypes of hematopoietic cancer, including overall non-Hodgkin lymphoma, overall $\mathrm{T}$ cell non-Hodgkin lymphoma (in aggregate), common histological types of B cell nonHodgkin lymphoma (diffuse large B cell lymphoma, follicular lymphoma, and chronic lymphocytic leukemia or small lymphocytic lymphoma), multiple myeloma, Hodgkin lymphoma (in aggregate) and myeloid leukemias (also in aggregate). We conducted further analyses stratified by natural hair color (lightred, blond or light brown; or dark-black or dark brown) for all endpoints. Tests for interaction were performed by adding interaction terms to the models and using log likelihood ratio tests comparing nested models to determine statistical significance.

We considered a series of sensitivity analyses. Firstly we performed $6,10,16$, and 20 year latency analyses (by assuming follow-up starts 6, 10, 16, and 20 years after assessments of exposures stopped in 1982) for overall cancer, basal cell carcinoma, breast cancer, and ovarian cancer. Secondly, to explore the potential timing of associations, we repeated analyses for these endpoints by restricting follow-up to the first 10 and 20 years after exposure assessments stopped. Given a proportion of participants $(9.09 \%)$ who were never users at baseline reported their first time of hair dye use in subsequent assessment cycles (1978, 1980, and 1982), we also conducted analyses by using baseline exposure information only. Statistical analyses were conducted by using SAS software (version 9.4 for UNIX; SAS Institute, Cary, NC, USA). All tests were two sided and $P$ values less than 0.05 were considered statistically significant.

\section{Patient and public involvement}

Participants were not involved in setting the research question or the outcome measures, nor were they involved in the design or implementation of the study. No participants were asked to advise on interpretation or writing up of the manuscript. The participants are updated on findings and developments of the Nurses' Health Study cohort through annual newsletters and the official website (https://www.nurseshealthstudy. org).

\section{Results}

\section{Population characteristics}

During 36 years of follow-up, a total of 20805 solid cancers (not including major non-melanoma skin cancers), 1807 hematopoietic cancers, 22560 basal cell carcinomas, and 2792 cutaneous squamous cell carcinomas were reported. Additionally, 4860 cancer related deaths were documented. Women whose natural hair color was blond or light brown were more likely to use permanent hair dyes, and those whose natural hair color was dark brown, black, and red were less likely to use permanent hair dye. Ever users were more likely to be smokers and consumed more alcohol than those reporting no history of personal permanent 
hair dye use. We did not observe any other major variations across self-reported personal permanent hair dye use (table 1).

Personal use of permanent hair dyes and cancer risk In multivariable analyses, we observed no significant association between status, duration, or frequency of use, cumulative dose, age at first use, or time since first use and the risk of overall solid cancer (not including major non-melanoma skin cancers) and overall hematopoietic cancer. No association was found between personal use of permanent hair dyes and risk of most of the specific cancer subtypes. In contrast, we did observe a slightly increased risk of basal cell carcinoma, and a lower risk of brain cancer and chronic lymphocytic leukemia or small lymphocytic lymphoma among ever users. Results from never or ever use and cumulative dose analyses were not consistent across endpoints. In dose dependent analyses, no dose dependency was observed for basal cell carcinoma. In contrast, a larger cumulative dose was associated with higher or potentially higher risks of overall breast cancer, which could reflect higher risks more specifically of estrogen receptor negative breast cancer, progesterone receptor negative breast cancer, hormone receptor negative breast cancer, and an apparent lack of association for receptor positive subtypes. The dose-response analyses also suggested dose dependent positive associations for ovarian

\begin{tabular}{|c|c|c|}
\hline \multirow[b]{2}{*}{ Characteristic } & \multicolumn{2}{|c|}{ Status of personal permanent hair dye use } \\
\hline & Non-user & Ever user \\
\hline No of participants (\%) & $79430(67.77)$ & $37770(32.23)$ \\
\hline Age (mean (SD)) & $42.65(7.22)$ & $43.23(7.19)$ \\
\hline \multicolumn{3}{|l|}{ Race } \\
\hline White & $96.27(76464)$ & $97.81(36941)$ \\
\hline Black & $2.55(2027)$ & $1.54(581)$ \\
\hline Other & $1.18(939)$ & $0.66(248)$ \\
\hline \multicolumn{3}{|l|}{ Natural hair color } \\
\hline Black & $3.62(2878)$ & $2.56(968)$ \\
\hline Dark brown & $34.32(27259)$ & $29.56(11166)$ \\
\hline Red & $3.65(2899)$ & $2.24(846)$ \\
\hline Light brown & $27.62(21942)$ & $32.45(12256)$ \\
\hline Blond & $8.02(6366)$ & $10.41(3930)$ \\
\hline Body mass index (mean (SD))* & $23.83(4.22)$ & $23.62(3.98)$ \\
\hline Body mass index at age 18 (mean (SD))* & $21.37(3.03)$ & $21.29(2.96)$ \\
\hline \multicolumn{3}{|l|}{ Smoking status } \\
\hline Never smoked & $47.33(37595)$ & $36.37(13737)$ \\
\hline Past smoker & $21.85(17357)$ & $25.99(9816)$ \\
\hline Current smoker ( 25 cigarettes/day) & $22.54(17906)$ & $26.83(10132)$ \\
\hline Current smoker ( $\geq 25$ cigarettes/day) & $8.27(6572)$ & $10.81(4085)$ \\
\hline \multicolumn{3}{|l|}{ Pack years of smoking } \\
\hline 0 & $48.42(38458)$ & $37.61(14204)$ \\
\hline$>0$ to 5 & $11.30(8974)$ & $12.74(4811)$ \\
\hline$>5$ to 15 & $14.84(11786)$ & $17.50(6610)$ \\
\hline$>15$ & $25.45(20211)$ & $32.15(12145)$ \\
\hline Alcohol intake (g/day; mean (SD)) & $5.89(10.17)$ & $7.35(11.24)$ \\
\hline \multicolumn{3}{|c|}{$\begin{array}{l}\text { Participants with a previous diagnosis of any cancer before or at baseline, or participants who reported no } \\
\text { information on personal use of permanent hair dyes were excluded. Denominators for percentage calculations } \\
\text { are of non-missing values. Percentages may not sum to } 100 \% \text { after rounding. } \\
{ }^{*} \text { Calculated as weight in kilograms divided by height in meters squared. }\end{array}$} \\
\hline
\end{tabular}

cancer, and a lower risk of chronic lymphocytic leukemia or small lymphocytic lymphoma.

We observed mixed results for never or ever use and cumulative dose of permanent hair dyes in analyses stratified by natural hair color for some endpoints, though the results were not consistent. Women with naturally dark hair who ever used permanent hair dyes had an increased risk of Hodgkin lymphoma (based on a limited number of cancers) and a lower risk of lung cancer compared with non-users, whereas this association was not found in women with naturally light hair. Higher or potentially higher risks of basal cell carcinoma and overall breast cancer were specifically observed among women with naturally light hair. No other important associations were observed for natural hair color. In dose dependent analyses, we observed higher or potentially higher risks of ovarian cancer and several specific breast cancers (estrogen receptor negative, progesterone receptor negative, hormone receptor negative) among women regardless of their nature hair color. Table 2, table 3, table 4, and table 5 partially summarize these findings, and supplementary tables 1-28 present detailed results.

In the spline analyses, we did not observe any statistically significant nonlinearity of the relation between cumulative dose and incidence of most of the specific cancers, except for $\mathrm{T}$ cell lymphoma. Supplementary figures 1-28 present the results.

\section{Personal use of permanent hair dyes and cancer mortality}

We explored the association between personal use of permanent hair dyes and cancer mortality. Multivariable analyses showed no significant association between status, duration, frequency, or cumulative dose and cancer related death, and stratified by natural hair color. The spline analysis showed no statistically significant nonlinear relation between cumulative dose and cancer related death (supplementary table 29 and supplementary fig 29).

\section{Personal use of permanent hair dyes and cancer risk and mortality (sensitivity analyses)}

Assumptions of various latencies did not materially change the main findings for the aggregated and site specific cancer endpoints, except for a possible increased ovarian cancer risk with longer latency among women with naturally light hair (supplementary tables 30-37). Similarly, we did not observe any major variation in the associations when follow-up was restricted to the first 10 and 20 years after exposure assessments stopped. However, there was a possible decreased breast cancer risk with longer follow-up among women with naturally light hair (all remained statistically significant), and a decreased ovarian cancer risk among women whose natural hair color was black (remained statistically significant within the first 20 years; supplementary tables 38-45). In analyses that used baseline exposure information only, the results remained similar, although we observed minor variations (supplementary table 46). 


\begin{tabular}{|c|c|c|c|c|c|c|c|}
\hline \multirow[b]{2}{*}{ Type of cancer } & \multicolumn{2}{|r|}{ Any hair color } & \multicolumn{2}{|r|}{ Dark hair color } & \multicolumn{2}{|r|}{ Light hair color } & \multirow[b]{2}{*}{$\begin{array}{l}\text { P value for } \\
\text { interaction }\end{array}$} \\
\hline & $\begin{array}{l}\text { No of } \\
\text { events }\end{array}$ & Hazard ratio $(95 \% \mathrm{Cl})$ & $\begin{array}{l}\text { No of } \\
\text { events }\end{array}$ & Hazard ratio $(95 \% \mathrm{Cl})$ & $\begin{array}{l}\text { No of } \\
\text { events }\end{array}$ & Hazard ratio $(95 \% \mathrm{Cl})$ & \\
\hline All cancers* & 22612 & $0.98(0.96$ to 1.01$)$ & 8389 & $1.00(0.96$ to 1.05$)$ & 9417 & 0.98 (0.94 to 1.02$)$ & 0.42 \\
\hline All solid cancers* & 20805 & $0.98(0.96$ to 1.01$)$ & 7648 & $0.99(0.95$ to 1.04$)$ & 8708 & 0.98 (0.94 to 1.02$)$ & 0.69 \\
\hline Basal cell carcinomat & 22560 & 1.05 (1.02 to 1.08$)$ & 7737 & $1.01(0.96$ to 1.06$)$ & 11334 & $1.06(1.02$ to 1.11$)$ & 0.21 \\
\hline $\begin{array}{l}\text { Cutaneous squamous } \\
\text { cell carcinomat }\end{array}$ & 2792 & 1.00 (0.93 to 1.09) & 959 & $1.02(0.89$ to 1.16$)$ & 1375 & 0.95 (0.85 to 1.06$)$ & 0.36 \\
\hline Melanomat & 1198 & 1.01 (0.89 to 1.14$)$ & 386 & $0.93(0.75$ to 1.16$)$ & 580 & $1.00(0.84$ to 1.19$)$ & 0.62 \\
\hline Breast cancer $\ddagger$ & 9252 & 1.02 (0.98 to 1.07 ) & 3565 & 1.06 (0.99 to 1.13$)$ & 3902 & 1.02 (0.96 to 1.09 ) & 0.38 \\
\hline Breast cancer $(E R+) \ddagger \S$ & 5905 & 1.00 (0.95 to 1.05$)$ & 2388 & 1.01 (0.93 to 1.10$)$ & 2595 & 1.01 (0.93 to 1.09 ) & 0.61 \\
\hline Breast cancer (ER-)‡§ & 1521 & $1.02(0.92$ to 1.14$)$ & 610 & 1.16 (0.98 to 1.37$)$ & 649 & 1.00 (0.85 to 1.17$)$ & 0.12 \\
\hline Breast cancer $(P R+) \neq \S$ & 4826 & 0.97 (0.92 to 1.03$)$ & 1933 & 0.99 (0.90 to 1.08$)$ & 2148 & 0.96 (0.88 to 1.05$)$ & 0.48 \\
\hline Breast cancer $(P R-) \neq \S$ & 2379 & 1.05 (0.97 to 1.15$)$ & 977 & 1.13 (0.99 to 1.29$)$ & 1003 & 1.09 (0.96 to 1.24$)$ & 0.48 \\
\hline Breast cancer $(\mathrm{ER}+/ \mathrm{PR}+) \neq \S$ & 4634 & 0.97 (0.91 to 1.03) & 1848 & 0.98 (0.89 to 1.07$)$ & 2079 & $0.96(0.88$ to 1.06$)$ & 0.58 \\
\hline Breast cancer $(E R+/ P R-) \neq \S$ & 1086 & $1.09(0.97$ to 1.24$)$ & 459 & $1.11(0.92$ to 1.35$)$ & 441 & $1.20(0.99$ to 1.45$)$ & 0.67 \\
\hline Breast cancer (ER-/PR-)‡§ & 1287 & $1.03(0.92$ to 1.15$)$ & 517 & $1.15(0.96$ to 1.38$)$ & 561 & $1.02(0.86$ to 1.21$)$ & 0.19 \\
\hline Ovarian cancer 9 & 1215 & 1.09 (0.97 to 1.22$)$ & 449 & 1.21 (1.00 to 1.47$)$ & 509 & $1.06(0.89$ to 1.27$)$ & 0.54 \\
\hline Colorectal cancer ${ }^{\star \star}$ & 2394 & $1.05(0.97$ to 1.14$)$ & 858 & 1.07 (0.93 to 1.23$)$ & 991 & $1.03(0.91$ to 1.18$)$ & 0.97 \\
\hline Bladder cancert† & 596 & $1.05(0.90$ to 1.24$)$ & 227 & $1.06(0.81$ to 1.38$)$ & 260 & 1.09 (0.85 to 1.39$)$ & 0.81 \\
\hline Kidney cancer & 477 & 1.03 (0.85 to 1.23$)$ & 184 & $0.99(0.73$ to 1.34$)$ & 190 & $1.13(0.84$ to 1.51$)$ & 0.42 \\
\hline Lung cancer & 2623 & $0.94(0.87$ to 1.01$)$ & 908 & $0.81(0.70$ to 0.93$)$ & 1017 & 0.97 (0.85 to 1.10$)$ & 0.06 \\
\hline Brain cancer & 277 & $0.72(0.56$ to 0.93$)$ & 100 & 0.91 (0.60 to 1.37) & 100 & $0.53(0.35$ to 0.82$)$ & 0.08 \\
\hline All hematopoietic cancers & 1807 & $1.00(0.91$ to 1.10$)$ & 741 & $1.08(0.93$ to 1.26$)$ & 709 & $0.94(0.81$ to 1.10$)$ & 0.14 \\
\hline All non-Hodgkin lymphomas & 1277 & 0.94 (0.84 to 1.05$)$ & 529 & 0.99 (0.83 to 1.18$)$ & 510 & 0.92 (0.77 to 1.09$)$ & 0.52 \\
\hline T cell lymphoma & 51 & $1.24(0.71$ to 2.17$)$ & 25 & 0.88 (0.38 to 2.04) & 15 & $1.64(0.56$ to 4.75$)$ & 0.26 \\
\hline Diffuse large B cell lymphoma & 190 & $1.06(0.79$ to 1.42$)$ & 76 & $1.16(0.72$ to 1.84$)$ & 79 & 0.87 (0.55 to 1.37$)$ & 0.45 \\
\hline Follicular lymphoma & 204 & 1.20 (0.91 to 1.59$)$ & 83 & $1.45(0.93$ to 2.25$)$ & 87 & $1.12(0.73$ to 1.72$)$ & 0.33 \\
\hline $\begin{array}{l}\text { Chronic lymphocytic leukemia or } \\
\text { small lymphocytic lymphoma }\end{array}$ & 272 & 0.69 (0.53 to 0.89) & 122 & $0.78(0.54$ to 1.14$)$ & 111 & $0.62(0.41$ to 0.92$)$ & 0.35 \\
\hline Hodgkin lymphomał & 70 & $1.32(0.82$ to 2.13$)$ & 24 & $3.89(1.61$ to 9.40$)$ & 31 & $0.70(0.33$ to 1.49$)$ & 0.004 \\
\hline Multiple myelomałł & 274 & $1.10(0.86$ to 1.40$)$ & 113 & $1.07(0.73$ to 1.56$)$ & 108 & $1.13(0.77$ to 1.67$)$ & 0.85 \\
\hline Myeloid leukemias & 170 & $0.99(0.72$ to 1.34$)$ & 59 & 1.17 (0.69 to 1.97$)$ & 64 & $0.90(0.55$ to 1.50$)$ & 0.46 \\
\hline Cancer related death§§ & 4860 & $0.96(0.91$ to 1.02$)$ & 1661 & $1.01(0.91$ to 1.11$)$ & 1801 & $0.94(0.85$ to 1.03$)$ & 0.32 \\
\hline
\end{tabular}

ER=estrogen receptor; $M E T=$ metabolic equivalent of task; $P R=$ progesterone receptor.

All models were adjusted for age (continuous, months), follow-up cycle (each two year interval), race (white, black, other), natural hair color (dark brown, light brown, black, blond, red, missing), cumulative average body mass index ( $(20.0,20.0-24.9,25.0-29.9,230.0)$, body mass index at age 18 ( $(20.0,20.0-24.9,25.0-29.9, \geq 30.0)$, smoking status (non-smoker, past smoker, current smoker $<25$ cigarettes/day, current smoker $\geq 25$ cigarettes/day), pack years of smoking $(0,>0$ to $5,>5$ to $15,>15)$, and alcohol intake $(0,0.1-4.9,5-14.9, \geq 15 \mathrm{~g} /$ day). In analyses stratified by natural hair color, models were not further adjusted for natural hair color. Any hair color included participants whose natural hair color was black, dark brown, red, blond, or light brown, or who had missing information on natural hair color. Dark natural hair color included participants with black and dark brown hair; light natural hair color covered participants with red, blond, and light brown hair. Participants were excluded from stratified analyses if they had missing information on natural hair color. Number of events among women with dark hair color and light hair color does not add up to total number of events in any hair color because of inclusion of women with missing hair color information in the any hair color group.

* Not including basal cell carcinoma and cutaneous squamous cell carcinoma.

†Models were additionally adjusted for childhood reaction to sun (practically none, some redness, burn, or painful burn/blisters), lifetime blistering sunburns (never, 1-2, 3-5, and $\geq 6$ times), number of moles on arms $(0,1-2,3-5$, and $\geq 6)$, and cumulative ultraviolet flux since baseline ( $\times 10^{-4}$ Robertson-Berger units: an estimate of amount of ultraviolet radiation reaching Earth's surface of residence within one year, fifths).

¥Models were additionally adjusted for menopausal status (premenopausal, postmenopausal), postmenopausal hormone use (no use, past use, current use), oral contraceptive use (no use, ever use), adolescent body size (average of diagram scores at ages 10 and 20 years; $1.0,1.5-2.0,2.5-3.0,3.5-4.0$, and $\geq 4.5$ ), age at menarche ( $(12,12-13$, and $\geq 14$ years), age at first birth $(<25,25-29$, and $\geq 30$ years), parity (nulliparous, parous), breastfeeding (ever, never), first degree family history of breast cancer (yes, no), history of benign breast disease (yes, no), and current mammography use (yes, no).

§Hormone receptor status was not available for all breast cancers.

IModels were additionally adjusted for menopausal status (premenopausal, postmenopausal), postmenopausal hormone use (no use, past use, current use), age at menarche ( $12,12-13$, and $\geq 14$ years), oral contraceptive use (no use, ever use), and parity (nulliparous, parous).

**Models were additionally adjusted for physical activity (MET hours/week, fifths), menopausal status (premenopausal, postmenopausal), postmenopausal hormone use (no use, past use, current use), family history of colorectal cancer (yes, no), history of diabetes mellitus (yes, no), screening colonoscopy or sigmoidoscopy in the previous two years (yes, no), regular use of aspirin (yes, no), regular use of non-aspirin non-steroidal anti-inflammatory drugs (yes, no), multivitamin use (yes, no), total calorie intake (kcal/day, fifths), red or processed meat intake (servings/day, fifths), and intake of fiber, folate, calcium, and vitamin D (fifths).

††Models were additionally adjusted for total fluid intake (mL/day, quarters).

¥¥Models were additionally adjusted for regular use of aspirin (yes, no).

§Models were additionally adjusted for physical activity (MET hours/week, fifths), menopausal status (premenopausal, postmenopausal), postmenopausal hormone use (no use, past use,

current use), parity (nulliparous, parous), regular use of aspirin (yes, no), regular use of non-aspirin non-steroidal anti-inflammatory drugs (yes, no), multivitamin use (yes, no), total calories intake (kcal/day, fifths), history of hypertension (yes, no), history of hypercholesterolemia (yes, no), and history of diabetes mellitus (yes, no).

\section{Discussion}

In this large prospective cohort study of US women, we observed no increase in risk of most cancers or cancer related mortality among personal users of permanent hair dyes, with the exception of basal cell carcinoma, breast cancer (estrogen receptor negative, progesterone receptor negative, and hormone receptor negative), and ovarian cancer. We observed mixed findings for some endpoints (Hodgkin lymphoma and basal cell carcinoma) in analyses stratified by natural hair color.

\section{Comparison with other studies}

Hematopoietic cancer, bladder cancer, breast cancer, and lung cancer are among the cancers most frequently investigated in relation to hair dye use. ${ }^{6}$ Our results differ from reports of a slightly increased 


\begin{tabular}{|c|c|c|c|c|c|c|c|c|}
\hline \multirow[b]{2}{*}{ Type of cancer } & \multicolumn{6}{|c|}{ Cumulative dose (women with any hair color) } & \multirow[b]{2}{*}{$\begin{array}{l}\text { Per } 50 \text { time } \\
\text { increment }\end{array}$} & \multirow[b]{2}{*}{$\begin{array}{l}\text { P value } \\
\text { for trend }\end{array}$} \\
\hline & $\begin{array}{l}\text { No of } \\
\text { events }\end{array}$ & Non-user & 1-99 times & 100-199 times & $\geq 200$ times & $\begin{array}{l}\mathrm{P} \text { value for } \\
\text { trendt }\end{array}$ & & \\
\hline All cancers* & 22612 & 1 (reference) & 0.98 (0.94 to 1.01$)$ & 0.98 (0.94 to 1.03$)$ & $1.00(0.96$ to 1.05$)$ & 0.94 & $1.00(0.99$ to 1.00$)$ & 0.74 \\
\hline All solid cancers ${ }^{\star}$ & 20805 & 1 & 0.97 (0.94 to 1.01$)$ & $0.99(0.95$ to 1.04$)$ & 1.00 (0.96 to 1.05$)$ & 0.99 & 1.00 (0.99 to 1.00$)$ & 0.64 \\
\hline Basal cell carcinoma§ & 22560 & 1 & $1.05(1.02$ to 1.09$)$ & $1.04(1.00$ to 1.09$)$ & $1.05(1.00$ to 1.09$)$ & 0.03 & $1.00(1.00$ to 1.01$)$ & 0.40 \\
\hline $\begin{array}{l}\text { Cutaneous squamous cell } \\
\text { carcinoma§ }\end{array}$ & 2792 & 1 & 1.00 (0.90 to 1.11$)$ & 1.03 (0.91 to 1.17 ) & 0.98 (0.86 to 1.12$)$ & 0.92 & 1.00 (0.99 to 1.01$)$ & 0.96 \\
\hline Melanoma§ & 1198 & 1 & $1.03(0.88$ to 1.20$)$ & 0.95 (0.77 to 1.17$)$ & $1.02(0.83$ to 1.26$)$ & 0.99 & 0.99 (0.97 to 1.02) & 0.59 \\
\hline Breast cancerf & 9252 & 1 & 1.01 (0.96 to 1.06$)$ & $0.99(0.92$ to 1.06$)$ & $1.09(1.02$ to 1.16$)$ & 0.04 & 1.00 (1.00 to 1.01$)$ & 0.17 \\
\hline Breast cancer $(\mathrm{ER}+) \boldsymbol{\eta}^{\star \star}$ & 5905 & 1 & $0.99(0.92$ to 1.06$)$ & 1.00 (0.92 to 1.09$)$ & $1.02(0.93$ to 1.11$)$ & 0.73 & $1.00(0.99$ to 1.01$)$ & 0.86 \\
\hline Breast cancer (ER-) $\|^{\star \star}$ & 1521 & 1 & $0.99(0.87$ to 1.13$)$ & 0.91 (0.76 to 1.09$)$ & $1.20(1.02$ to 1.41$)$ & 0.09 & $1.02(1.00$ to 1.03$)$ & 0.03 \\
\hline Breast cancer $(\mathrm{PR}+) \boldsymbol{\eta}^{\star \star}$ & 4826 & 1 & 0.94 (0.87 to 1.02$)$ & $0.99(0.90$ to 1.09$)$ & $1.02(0.93$ to 1.12$)$ & 0.71 & $1.00(0.99$ to 1.01$)$ & 0.81 \\
\hline Breast cancer (PR-) $\boldsymbol{\eta}^{\star \star}$ & 2379 & 1 & $1.06(0.95$ to 1.17$)$ & $0.98(0.86$ to 1.13$)$ & $1.12(0.98$ to 1.28$)$ & 0.16 & 1.01 (1.00 to 1.02$)$ & 0.06 \\
\hline Breast cancer $(\mathrm{ER}+/ \mathrm{PR}+) \|^{\star \star}$ & 4634 & 1 & 0.93 (0.86 to 1.01$)$ & $0.99(0.90$ to 1.09$)$ & $1.03(0.93$ to 1.13$)$ & 0.62 & $1.00(0.99$ to 1.01$)$ & 0.87 \\
\hline Breast cancer (ER+/PR-) $\rrbracket^{\star \star}$ & 1086 & 1 & $1.18(1.01$ to 1.37$)$ & 1.08 (0.89 to 1.32$)$ & $0.94(0.76$ to 1.16$)$ & 0.73 & 1.00 (0.98 to 1.02$)$ & 0.96 \\
\hline Breast cancer (ER-/PR-) ף** & 1287 & 1 & $0.97(0.83$ to 1.12$)$ & 0.91 (0.75 to 1.10$)$ & 1.28 (1.08 to 1.52$)$ & 0.03 & $1.02(1.01$ to 1.03$)$ & 0.006 \\
\hline Ovarian cancert† & 1215 & 1 & $1.00(0.86$ to 1.16$)$ & 1.20 (1.01 to 1.44$)$ & 1.15 (0.96 to 1.37$)$ & 0.046 & 1.01 (0.99 to 1.02$)$ & 0.33 \\
\hline 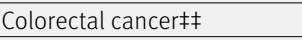 & 2394 & 1 & $1.02(0.92$ to 1.14$)$ & $1.08(0.94$ to 1.23$)$ & $1.08(0.95$ to 1.23$)$ & 0.16 & $1.00(0.99$ to 1.02$)$ & 0.58 \\
\hline Bladder cancer£§ & 596 & 1 & $1.05(0.85$ to 1.30$)$ & $1.02(0.78$ to 1.33$)$ & $1.10(0.85$ to 1.42$)$ & 0.51 & $1.00(0.98$ to 1.03$)$ & 0.73 \\
\hline Kidney cancer & 477 & 1 & $1.06(0.84$ to 1.33$)$ & $1.02(0.76$ to 1.39$)$ & $0.97(0.71$ to 1.32$)$ & 0.88 & 0.99 (0.95 to 1.02$)$ & 0.50 \\
\hline Lung cancer & 2623 & 1 & $0.96(0.87$ to 1.06$)$ & $0.93(0.82$ to 1.06$)$ & $0.89(0.78$ to 1.01$)$ & 0.06 & $0.99(0.97$ to 1.00$)$ & 0.08 \\
\hline Brain cancer & 277 & 1 & $0.68(0.48$ to 0.96$)$ & $0.78(0.51$ to 1.19$)$ & $0.73(0.48$ to 1.11$)$ & 0.09 & $0.96(0.92$ to 1.01$)$ & 0.15 \\
\hline All hematopoietic cancers & 1807 & 1 & $1.04(0.92$ to 1.17$)$ & $0.90(0.76$ to 1.05$)$ & 1.02 (0.88 to 1.19$)$ & 0.81 & $1.00(0.99$ to 1.02$)$ & 0.72 \\
\hline All non-Hodgkin lymphomas & 1277 & 1 & $0.98(0.85$ to 1.13$)$ & 0.81 (0.66 to 0.99) & 0.98 (0.82 to 1.18$)$ & 0.40 & $1.00(0.98$ to 1.02$)$ & 0.95 \\
\hline T cell lymphoma & 51 & 1 & 1.54 (0.81 to 2.95$)$ & 0.83 (0.29 to 2.38$)$ & 1.07 (0.41 to 2.80$)$ & 0.97 & $0.96(0.85$ to 1.09$)$ & 0.50 \\
\hline $\begin{array}{l}\text { Diffuse large B } \\
\text { cell lymphoma }\end{array}$ & 190 & 1 & 0.94 (0.64 to 1.38$)$ & 1.01 (0.63 to 1.64$)$ & 1.34 (0.87 to 2.06$)$ & 0.21 & $1.02(1.00$ to 1.05$)$ & 0.06 \\
\hline Follicular lymphoma & 204 & 1 & $1.42(1.02$ to 1.98$)$ & 0.89 (0.54 to 1.47$)$ & $1.10(0.69$ to 1.75$)$ & 0.91 & $1.02(0.99$ to 1.05$)$ & 0.16 \\
\hline $\begin{array}{l}\text { Chronic lymphocytic } \\
\text { leukemia or small } \\
\text { lymphocytic lymphoma }\end{array}$ & 272 & 1 & 0.69 (0.49 to 0.96$)$ & $0.67(0.44$ to 1.04$)$ & 0.71 (0.47 to 1.08$)$ & 0.047 & $0.95(0.90$ to 1.00$)$ & 0.06 \\
\hline Hodgkin lymphomaףी & 70 & 1 & $1.30(0.73$ to 2.34$)$ & 1.48 (0.71 to 3.09$)$ & 1.19 (0.52 to 2.69$)$ & 0.50 & $1.03(0.95$ to 1.11$)$ & 0.49 \\
\hline Multiple myelomaףף & 274 & 1 & $1.19(0.88$ to 1.61$)$ & 1.13 (0.77 to 1.66$)$ & 0.90 (0.59 to 1.37$)$ & 0.78 & 0.99 (0.94 to 1.03$)$ & 0.52 \\
\hline Myeloid leukemias & 170 & 1 & $1.06(0.72$ to 1.55$)$ & $0.50(0.25$ to 1.00$)$ & $1.32(0.84$ to 2.05$)$ & 0.62 & 1.01 (0.99 to 1.04$)$ & 0.34 \\
\hline Cancer related death ${ }^{\star \star \star}$ & 4860 & 1 & $0.97(0.90$ to 1.05$)$ & 0.91 (0.83 to 1.01$)$ & 0.99 (0.91 to 1.09$)$ & 0.52 & 1.00 (0.99 to 1.01$)$ & 0.54 \\
\hline
\end{tabular}

ER=estrogen receptor; PR=progesterone receptor.

All models were adjusted for age, follow-up cycle, race, natural hair color, cumulative average body mass index, body mass index at age 18, smoking status, pack years of smoking and alcohol intake. In analyses stratified by natural hair color, models were not further adjusted for natural hair color. Any hair color included participants whose

natural hair color was black, dark brown, red, blond, or light brown, or who had missing information on natural hair color. Cumulative dose of permanent hair dye use was

calculated by multiplying average frequency of use (times per year) by duration of use (years).

*Not including basal cell carcinoma and cutaneous squamous cell carcinoma.

tP value for trend was calculated by using mid-point of each category of cumulative dose in times.

$\ddagger$ P value for trend was calculated by using cumulative dose in times as continuous variable.

§Models were additionally adjusted for childhood reaction to sun, lifetime blistering sunburns, number of moles on arms, and cumulative ultraviolet flux since baseline.

IModels were additionally adjusted for menopausal status, postmenopausal hormone use, oral contraceptive use, adolescent body size, age at menarche, age at first birth, parity, breastfeeding,

first degree family history of breast cancer, history of benign breast disease, and current mammography use.

${ }^{*}$ Hormone receptor status was not available for all breast cancers.

††Models were additionally adjusted for menopausal status, postmenopausal hormone use, age at menarche, oral contraceptive use, and parity.

¥¥Models were additionally adjusted for physical activity, menopausal status, postmenopausal hormone use, family history of colorectal cancer, history of diabetes mellitus, screening

colonoscopy or sigmoidoscopy in the previous two years, regular use of aspirin, regular use of non-aspirin non-steroidal anti-inflammatory drugs, multivitamin use, total calorie intake, red or

processed meat intake, and intake of fiber, folate, calcium, and vitamin D.

$\S \S$ Models were additionally adjusted for total fluid intake.

II Models were additionally adjusted for regular use of aspirin.

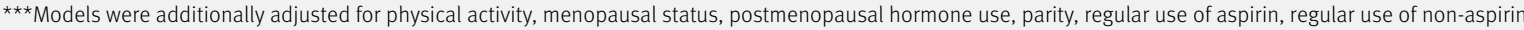

non-steroidal anti-inflammatory drugs, multivitamin use, total calorie intake, history of hypertension, history of hypercholesterolemia, and history of diabetes mellitus.

relative risk of overall hematopoietic cancer $^{6} 12$ (especially among people who use permanent hair dye, ${ }^{12}$ dark hair dye, ${ }^{12}$ and ever users of hair dyes before $1980^{12}$ ). Our findings update the first prospective cohort study of hematopoietic cancer among women who use permanent hair dye conducted in 1994 with participants from the Nurses' Health Study. ${ }^{17}$ With considerably longer follow-up, our findings generally replicate the previous report of no material increase in the risk of overall or major subcategories of hematopoietic cancer, although we note that the previous study preceded the modern
WHO classification of hematological cancers (therefore subgroup specific findings might not be directly comparable). ${ }^{17}$ The observation of higher Hodgkin lymphoma risk among women who were presumed to use dark colored permanent hair dye is novel and warrants cautious interpretation. This finding is based on a limited number of women and we had insufficient histological subtype information to restrict the analysis to classic Hodgkin lymphoma types, which might have a different cause from non-classical types. ${ }^{34}$ Additionally, we cannot rule out an influence of residual or otherwise uncontrolled confounding, for 
example, by factors for which we lacked information (such as history of oncogenic infections).

Our study corroborates the null evidence on higher risk of bladder cancer among personal users of hair dyes with any hair colors reported by prior meta-analyses, ${ }^{10}$ but is inconsistent with the previously reported elevated risk of bladder cancer among dark colored dye users $^{10}$ and the reported null finding for breast cancer among any colored dye users. ${ }^{611}$ Evidence from these previous meta-analyses ${ }^{6} 10-12$ is not conclusive and might have been influenced by the following factors: not discriminating between personal and occupational exposure $^{11}$; an inability to distinguish between use of permanent and non-permanent hair dyes ${ }^{11}$; the design of the included studies (predominantly case control studies with relatively limited power) ${ }^{6}{ }^{10-12}$; non-evaluation of several critical domains of exposure history (eg, duration, frequency, and cumulative dose of use) owing to lowest common denominator of the evaluated studies $^{69-12}$; and diagnostic challenges. ${ }^{12}$

African Americans have higher risks of presenting with estrogen receptor negative and progesterone receptor negative breast cancer than non-Hispanic white people in the US. ${ }^{35}{ }^{36}$ Interestingly, a recent US cohort study observed considerably higher breast cancer risk in black women and a borderline increased

\begin{abstract}
Table 4 | Cox proportional hazard ratios ( $95 \%$ confidence intervals) for overall and specific cancer incidence and cancer related deaths among women
\end{abstract} in the Nurses' Health Study with dark hair color according to cumulative dose of permanent hair dye use

Cumulative dose (women with dark hair color)

\begin{tabular}{|c|c|c|c|c|c|c|c|c|}
\hline \multirow[b]{2}{*}{ Type of cancer } & & \multirow[b]{2}{*}{$\begin{array}{l}\text { Per } 50 \text { time } \\
\text { increment }\end{array}$} & \multirow[b]{2}{*}{$\begin{array}{l}\text { P value } \\
\text { for trend } \neq\end{array}$} \\
\hline & $\begin{array}{l}\text { No of } \\
\text { events }\end{array}$ & Non-user & 1-99 times & 100-199 times & $\geq 200$ times & $\begin{array}{l}\text { P value for } \\
\text { trendt }\end{array}$ & & \\
\hline All cancers* & 8389 & 1 (reference) & 1.02 (0.96 to 1.08$)$ & 0.99 (0.92 to 1.06$)$ & 0.97 (0.90 to 1.05$)$ & 0.47 & $1.00(0.99$ to 1.01$)$ & 0.44 \\
\hline All solid cancers* & 7648 & 1 & 1.00 (0.95 to 1.06$)$ & 1.01 (0.93 to 1.08$)$ & 0.96 (0.88 to 1.04$)$ & 0.38 & 1.00 (0.99 to 1.01$)$ & 0.39 \\
\hline Basal cell carcinoma§ & 7737 & 1 & $0.98(0.93$ to 1.05$)$ & $1.03(0.96$ to 1.11$)$ & 1.04 (0.96 to 1.13$)$ & 0.25 & $1.00(1.00$ to 1.01$)$ & 0.29 \\
\hline $\begin{array}{l}\text { Cutaneous squamous } \\
\text { cell carcinoma§ }\end{array}$ & 959 & 1 & 0.98 (0.82 to 1.16$)$ & 1.04 (0.84 to 1.28$)$ & 1.07 (0.86 to 1.34$)$ & 0.51 & 1.01 (0.99 to 1.03$)$ & 0.36 \\
\hline Melanoma§ & 386 & 1 & $0.92(0.70$ to 1.21$)$ & 0.90 (0.63 to 1.29$)$ & 0.99 (0.67 to 1.44$)$ & 0.79 & 1.00 (0.96 to 1.04$)$ & 0.93 \\
\hline Breast cancern & 3565 & 1 & 1.08 (0.99 to 1.18$)$ & $1.02(0.91$ to 1.14$)$ & 1.05 (0.93 to 1.18$)$ & 0.44 & 1.01 (0.99 to 1.02$)$ & 0.39 \\
\hline Breast cancer $(\mathrm{ER}+) \boldsymbol{\eta}^{\star \star}$ & 2388 & 1 & 1.03 (0.93 to 1.15$)$ & $0.99(0.86$ to 1.14$)$ & 1.00 (0.86 to 1.16$)$ & 0.96 & 1.00 (0.99 to 1.02$)$ & 0.57 \\
\hline Breast cancer (ER-) $\|^{\star \star}$ & 610 & 1 & $1.22(0.99$ to 1.49$)$ & 1.05 (0.80 to 1.38$)$ & 1.16 (0.86 to 1.55$)$ & 0.35 & 1.01 (0.98 to 1.04$)$ & 0.50 \\
\hline Breast cancer $(\mathrm{PR}+) \boldsymbol{\eta}^{\star \star}$ & 1933 & 1 & 1.00 (0.89 to 1.13$)$ & $0.98(0.84$ to 1.14$)$ & $0.97(0.82$ to 1.14$)$ & 0.64 & 1.00 (0.98 to 1.02$)$ & 0.98 \\
\hline Breast cancer (PR-) $\boldsymbol{\eta}^{\star \star}$ & 977 & 1 & 1.15 (0.98 to 1.36$)$ & 1.06 (0.86 to 1.32$)$ & 1.15 (0.91 to 1.44$)$ & 0.23 & 1.01 (1.00 to 1.03$)$ & 0.12 \\
\hline Breast cancer $(E R+/ P R+) \|^{\star \star}$ & 1848 & 1 & 0.98 (0.86 to 1.10$)$ & 0.97 (0.83 to 1.13$)$ & 0.98 (0.83 to 1.17$)$ & 0.75 & 1.00 (0.98 to 1.02$)$ & 0.86 \\
\hline Breast cancer (ER+/PR-) $\boldsymbol{\eta}^{\star \star}$ & 459 & 1 & 1.15 (0.90 to 1.46$)$ & $1.14(0.84$ to 1.54$)$ & $1.02(0.72$ to 1.43$)$ & 0.72 & 1.01 (0.99 to 1.04$)$ & 0.33 \\
\hline Breast cancer (ER-/PR-) $\|^{\star \star}$ & 517 & 1 & 1.18 (0.94 to 1.47$)$ & $1.00(0.74$ to 1.36$)$ & 1.28 (0.94 to 1.73$)$ & 0.18 & $1.02(0.99$ to 1.04$)$ & 0.19 \\
\hline Ovarian cancert† & 449 & 1 & $1.10(0.86$ to 1.41$)$ & $1.36(1.02$ to 1.82$)$ & 1.28 (0.93 to 1.77$)$ & 0.04 & $1.03(1.00$ to 1.06$)$ & 0.09 \\
\hline Colorectal cancer $\neq \ddagger$ & 858 & 1 & $1.04(0.87$ to 1.25$)$ & $1.13(0.91$ to 1.40$)$ & $1.08(0.85$ to 1.36$)$ & 0.36 & 1.01 (0.99 to 1.03$)$ & 0.50 \\
\hline Bladder cancer£§ & 227 & 1 & $1.24(0.90$ to 1.71$)$ & $1.02(0.67$ to 1.57$)$ & 0.73 (0.43 to 1.23$)$ & 0.31 & $0.98(0.92$ to 1.04$)$ & 0.44 \\
\hline Kidney cancer & 184 & 1 & $1.02(0.70$ to 1.49$)$ & $1.14(0.72$ to 1.82$)$ & 0.71 (0.38 to 1.33) & 0.48 & $0.96(0.90$ to 1.04$)$ & 0.33 \\
\hline Lung cancer & 908 & 1 & $0.86(0.72$ to 1.02$)$ & 0.79 (0.63 to 0.99$)$ & 0.73 (0.57 to 0.94$)$ & 0.003 & $0.96(0.93$ to 0.99$)$ & 0.005 \\
\hline Brain cancer & 100 & 1 & 1.07 (0.65 to 1.75$)$ & 0.65 (0.29 to 1.42$)$ & $0.84(0.40$ to 1.78$)$ & 0.42 & $0.96(0.87$ to 1.06$)$ & 0.39 \\
\hline All hematopoietic cancers & 741 & 1 & 1.21 (1.01 to 1.45$)$ & 0.81 (0.62 to 1.06) & $1.14(0.89$ to 1.46$)$ & 0.75 & $1.00(0.97$ to 1.03$)$ & 0.89 \\
\hline All non-Hodgkin lymphomas & 529 & 1 & 1.09 (0.87 to 1.35$)$ & 0.69 (0.49 to 0.96$)$ & 1.13 (0.84 to 1.52$)$ & 0.92 & 0.99 (0.96 to 1.03$)$ & 0.72 \\
\hline T cell lymphoma & 25 & 1 & 1.18 (0.44 to 3.14$)$ & $0.35(0.05$ to 2.66$)$ & $0.90(0.20$ to 4.04$)$ & 0.60 & $0.93(0.75$ to 1.16$)$ & 0.53 \\
\hline Diffuse large B cell lymphoma & 76 & 1 & 1.22 (0.68 to 2.18 ) & 0.88 (0.39 to 1.98$)$ & 1.37 (0.65 to 2.87 ) & 0.55 & $1.00(0.91$ to 1.10$)$ & 0.99 \\
\hline Follicular lymphoma & 83 & 1 & 1.67 (0.98 to 2.83$)$ & 1.37 (0.69 to 2.68$)$ & $1.13(0.52$ to 2.45$)$ & 0.61 & 1.00 (0.93 to 1.09$)$ & 0.94 \\
\hline $\begin{array}{l}\text { Chronic lymphocytic } \\
\text { leukemia or small } \\
\text { lymphocytic lymphoma }\end{array}$ & 122 & 1 & 53 to 1.38$)$ & 0.54 (0.26 to 1.12$)$ & 1.69) & 0.38 & 0.95 (0.87 to 1.04) & 0.25 \\
\hline Hodgkin lymphomaףी & 24 & 1 & 3.16 (1.14 to 8.77$)$ & $5.90(1.83$ to 19.10$)$ & $4.06(0.97$ to 16.90$)$ & 0.01 & $1.13(1.00$ to 1.29$)$ & 0.054 \\
\hline Multiple myelomaףी & 113 & 1 & $1.40(0.90$ to 2.19$)$ & $0.93(0.49$ to 1.77$)$ & $0.56(0.24$ to 1.31$)$ & 0.21 & 0.94 (0.85 to 1.03$)$ & 0.21 \\
\hline Myeloid leukemias & 59 & 1 & 1.64 (0.91 to 2.97$)$ & $0.18(0.02$ to 1.32$)$ & 1.24 (0.54 to 2.86$)$ & 0.88 & $1.03(0.95$ to 1.11$)$ & 0.46 \\
\hline Cancer-related death*** & 1661 & 1 & 1.07 (0.95 to 1.22$)$ & $0.92(0.78$ to 1.09$)$ & $0.97(0.82$ to 1.15$)$ & 0.50 & 1.00 (0.98 to 1.01$)$ & 0.71 \\
\hline
\end{tabular}

ER=estrogen receptor. $P R=$ progesterone receptor.

All models were adjusted for age, follow-up cycle, race, natural hair color, cumulative average body mass index, body mass index at age 18, smoking status, pack years of smoking, and alcohol intake. In analyses stratified by natural hair color, models were not further adjusted for natural hair color. Included participants whose natural hair color was black or dark brown. Cumulative dose of permanent hair dye use was calculated by multiplying average frequency of use (times per year) by duration of use (years).

*Not including basal cell carcinoma and cutaneous squamous cell carcinoma.

TP value for trend was calculated by using the mid-point of each category of cumulative dose in times.

$\ddagger P$ value for trend was calculated by using cumulative dose in times as continuous variable.

§Models were additionally adjusted for childhood reaction to sun, lifetime blistering sunburns, number of moles on arms, and cumulative ultraviolet flux since baseline.

१Models were additionally adjusted for menopausal status, postmenopausal hormone use, oral contraceptive use, adolescent body size, age at menarche, age at first birth, parity, breastfeeding,

first degree family history of breast cancer, history of benign breast disease, and current mammography use.

$\star \star$ Hormone receptor status was not available for all breast cancers.

†+Models were additionally adjusted for menopausal status, postmenopausal hormone use, age at menarche, oral contraceptive use, and parity.

$\ddagger \ddagger$ Models were additionally adjusted for physical activity, menopausal status, postmenopausal hormone use, family history of colorectal cancer, history of diabetes mellitus, screening

colonoscopy or sigmoidoscopy in the previous two years, regular use of aspirin, regular use of non-aspirin non-steroidal anti-inflammatory drugs, multivitamin use, total calorie intake, red or processed meat intake, and intake of fiber, folate, calcium, and vitamin D.

$\S \S$ Models were additionally adjusted for total fluid intake.

१९Models were additionally adjusted for regular use of aspirin.

${ }_{\star * \star}$ Models were additionally adjusted for physical activity, menopausal status, postmenopausal hormone use, parity, regular use of aspirin, regular use of non-aspirin non-steroidal anti-

inflammatory drugs, multivitamin use, total calories intake, history of hypertension, history of hypercholesterolemia, and history of diabetes mellitus. 
risk among white women who used permanent hair dyes, ${ }^{3738}$ which is largely consistent with our findings among US women with predominantly European ancestry. In particular, this recent study detected potential differences by estrogen receptor status; the risk associated with permanent hair dye appeared to be specifically increased for estrogen receptor negative breast cancer compared with estrogen receptor positive breast cancer. ${ }^{37}$ Our study, which was based on a larger number of women with breast cancer and more refined confounding control, ${ }^{39}$ observed similar findings for estrogen receptor negative breast cancers. Additionally, our study performed stratification analyses according to progesterone receptor status, and risk was similarly increased for progesterone receptor negative and hormone receptor negative breast cancer.

Evidence remains inadequate for other cancers. Individual or pooled relative risks were increased for several specific brain cancers, ${ }^{6} 4041$ basal cell carcinoma, $^{42}$ ovarian cancer, ${ }^{6}$ lung cancer, ${ }^{43}$ prostate cancer, ${ }^{44}$ cancer of the salivary glands, ${ }^{6}$ and neuroblastoma in offspring ${ }^{45-47}$ in previous studies, but not for cervical cancer ${ }^{6}$ and melanoma. ${ }^{6}$ However, these studies had similar limitations to those discussed above. Our current study, overcoming most of the major limitations in previous investigations, reported no positive association between ever personal use of permanent hair dyes and risk of cutaneous

\begin{tabular}{|c|c|c|c|c|c|c|c|c|}
\hline \multirow[b]{2}{*}{ Types of cancer } & \multicolumn{6}{|c|}{ Cumulative dose (women with light hair color) } & \multirow[b]{2}{*}{$\begin{array}{l}\text { Per } 50 \text { time } \\
\text { increment }\end{array}$} & \multirow[b]{2}{*}{$\begin{array}{l}\text { P value for } \\
\text { trend } \neq\end{array}$} \\
\hline & $\begin{array}{l}\text { No of } \\
\text { events }\end{array}$ & Non-user & 1-99 times & 100-199 times & $\geq 200$ times & $\begin{array}{l}\text { P value for } \\
\text { trendt }\end{array}$ & & \\
\hline All cancers* & 9417 & 1 (reference) & $0.95(0.90$ to 1.00$)$ & $0.98(0.92$ to 1.05$)$ & $1.03(0.97$ to 1.10$)$ & 0.36 & $1.00(1.00$ to 1.01$)$ & 0.59 \\
\hline All solid cancers ${ }^{\star}$ & 8708 & 1 & $0.95(0.90$ to 1.00$)$ & $0.97(0.91$ to 1.04$)$ & $1.05(0.98$ to 1.12$)$ & 0.25 & $1.00(1.00$ to 1.01$)$ & 0.59 \\
\hline Basal cell carcinoma§ & 11334 & 1 & 1.09 (1.04 to 1.15$)$ & $1.03(0.97$ to 1.10$)$ & $1.04(0.98$ to 1.11$)$ & 0.23 & $1.00(0.99$ to 1.01$)$ & 0.96 \\
\hline $\begin{array}{l}\text { Cutaneous squamous } \\
\text { cell carcinoma§ }\end{array}$ & 1375 & 1 & $0.97(0.85$ to 1.12$)$ & $1.00(0.84$ to 1.19$)$ & $0.86(0.72$ to 1.03$)$ & 0.15 & $0.98(0.96$ to 1.00$)$ & 0.09 \\
\hline Melanoma§ & 580 & 1 & 1.07 (0.86 to 1.32$)$ & 0.90 (0.68 to 1.20$)$ & 0.96 (0.73 to 1.28$)$ & 0.60 & 0.99 (0.96 to 1.02$)$ & 0.42 \\
\hline Breast cancer & 3902 & 1 & 0.97 (0.89 to 1.05$)$ & $0.99(0.89$ to 1.10$)$ & $1.16(1.05$ to 1.28$)$ & 0.006 & 1.01 (1.00 to 1.02$)$ & 0.02 \\
\hline Breast cancer $(E R+) \|^{\star \star}$ & 2595 & 1 & $0.95(0.86$ to 1.06$)$ & $1.03(0.91$ to 1.17$)$ & 1.08 (0.95 to 1.22$)$ & 0.17 & $1.00(0.99$ to 1.02$)$ & 0.50 \\
\hline Breast cancer (ER-) ף ${ }^{\star \star}$ & 649 & 1 & 0.91 (0.74 to 1.12$)$ & 0.85 (0.64 to 1.11$)$ & 1.31 (1.04 to 1.64$)$ & 0.07 & $1.02(1.00$ to 1.04$)$ & 0.03 \\
\hline Breast cancer $(\mathrm{PR}+) \rrbracket^{\star *}$ & 2148 & 1 & 0.88 (0.79 to 0.99$)$ & $1.00(0.87$ to 1.15$)$ & 1.07 (0.94 to 1.23$)$ & 0.25 & 1.01 (0.99 to 1.02$)$ & 0.47 \\
\hline Breast cancer (PR-) $\boldsymbol{\eta}^{\star \star}$ & 1003 & 1 & $1.06(0.90$ to 1.25$)$ & $1.00(0.81$ to 1.23$)$ & $1.24(1.02$ to 1.49$)$ & 0.06 & $1.02(1.00$ to 1.03$)$ & 0.07 \\
\hline Breast cancer (ER+/PR+) $\|^{\star \star}$ & 2079 & 1 & 0.88 (0.79 to 0.99$)$ & $1.00(0.87$ to 1.16$)$ & $1.08(0.94$ to 1.24$)$ & 0.21 & 1.01 (0.99 to 1.02$)$ & 0.48 \\
\hline Breast cancer (ER+/PR-) $\|^{\star \star}$ & 441 & 1 & $1.28(1.01$ to 1.62$)$ & $1.20(0.89$ to 1.61$)$ & $1.06(0.78$ to 1.45$)$ & 0.60 & $1.00(0.97$ to 1.03$)$ & 0.90 \\
\hline Breast cancer (ER-/PR-) $\|^{\star \star}$ & 561 & 1 & $0.91(0.72$ to 1.14$)$ & $0.85(0.64$ to 1.14$)$ & $1.38(1.09$ to 1.76$)$ & 0.03 & $1.02(1.00$ to 1.05$)$ & 0.02 \\
\hline Ovarian cancert† & 509 & 1 & $0.89(0.70$ to 1.13$)$ & 1.21 (0.93 to 1.57$)$ & $1.24(0.95$ to 1.61$)$ & 0.048 & $1.02(0.99$ to 1.04$)$ & 0.16 \\
\hline Colorectal cancer $\neq \ddagger$ & 991 & 1 & $1.00(0.85$ to 1.18$)$ & $0.96(0.78$ to 1.19$)$ & $1.17(0.97$ to 1.42$)$ & 0.17 & $1.01(0.99$ to 1.02$)$ & 0.43 \\
\hline Bladder cancer§§ & 260 & 1 & 0.99 (0.72 to 1.37$)$ & 1.00 (0.67 to 1.49$)$ & 1.34 (0.94 to 1.90$)$ & 0.14 & 1.00 (0.96 to 1.04$)$ & 0.99 \\
\hline Kidney cancer & 190 & 1 & $1.22(0.85$ to 1.74$)$ & $0.95(0.58$ to 1.54$)$ & $1.15(0.74$ to 1.81$)$ & 0.70 & $0.99(0.93$ to 1.04$)$ & 0.59 \\
\hline Lung cancer & 1017 & 1 & $0.95(0.81$ to 1.11$)$ & $1.08(0.89$ to 1.31$)$ & $0.90(0.74$ to 1.11$)$ & 0.56 & $0.99(0.97$ to 1.01$)$ & 0.30 \\
\hline Brain cancer & 100 & 1 & $0.43(0.23$ to 0.79$)$ & $0.74(0.39$ to 1.41$)$ & $0.52(0.25$ to 1.10$)$ & 0.08 & $0.93(0.84$ to 1.03$)$ & 0.15 \\
\hline All hematopoietic cancers & 709 & 1 & $0.92(0.76$ to 1.11$)$ & $1.04(0.83$ to 1.31$)$ & $0.89(0.70$ to 1.14$)$ & 0.52 & $1.00(0.98$ to 1.02$)$ & 0.95 \\
\hline All non-Hodgkin lymphomas & 510 & 1 & $0.90(0.72$ to 1.14$)$ & $0.99(0.75$ to 1.31$)$ & $0.86(0.64$ to 1.15$)$ & 0.39 & $1.00(0.97$ to 1.03$)$ & 0.93 \\
\hline T cell lymphoma & 15 & 1 & $1.97(0.58$ to 6.71$)$ & $2.11(0.50$ to 8.91$)$ & $0.66(0.08$ to 5.61$)$ & 0.90 & $0.94(0.76$ to 1.17$)$ & 0.57 \\
\hline Diffuse large B cell lymphoma & 79 & 1 & $0.77(0.42$ to 1.41$)$ & $1.03(0.51$ to 2.05$)$ & $0.90(0.44$ to 1.86$)$ & 0.87 & $1.03(0.96$ to 1.09$)$ & 0.44 \\
\hline Follicular lymphoma & 87 & 1 & $1.30(0.78$ to 2.17$)$ & $0.69(0.31$ to 1.56$)$ & $1.23(0.64$ to 2.35$)$ & 0.84 & $1.02(0.99$ to 1.05$)$ & 0.27 \\
\hline $\begin{array}{l}\text { Chronic lymphocytic leukemia/ } \\
\text { small lymphocytic lymphoma }\end{array}$ & 111 & 1 & $0.54(0.31$ to 0.93$)$ & $0.77(0.41$ to 1.43$)$ & $0.62(0.32$ to 1.20$)$ & 0.14 & $0.95(0.88$ to 1.04$)$ & 0.28 \\
\hline Hodgkin lymphomanף & 31 & 1 & $0.62(0.22$ to 1.71$)$ & 0.83 (0.24 to 2.86$)$ & $0.72(0.21$ to 2.47$)$ & 0.60 & $1.01(0.90$ to 1.14$)$ & 0.85 \\
\hline Multiple myelomaף & 108 & 1 & $1.18(0.73$ to 1.91$)$ & $1.20(0.67$ to 2.13$)$ & $0.99(0.53$ to 1.87$)$ & 0.90 & $0.99(0.93$ to 1.05$)$ & 0.69 \\
\hline Myeloid leukemias & 64 & 1 & 0.75 (0.38 to 1.48$)$ & 0.85 (0.37 to 1.92$)$ & 1.29 (0.61 to 2.70$)$ & 0.60 & 1.03 (0.95 to 1.12$)$ & 0.41 \\
\hline Cancer related death ${ }^{\star \star \star}$ & 1801 & 1 & $0.93(0.83$ to 1.05$)$ & $0.91(0.78$ to 1.06$)$ & $0.98(0.85$ to 1.14$)$ & 0.62 & $1.00(0.98$ to 1.01$)$ & 0.59 \\
\hline
\end{tabular}

ER=estrogen receptor: $P R=$ progesterone receptor.

All models were adjusted for age, follow-up cycle, race, natural hair color, cumulative average BMI, BMI at age 18, smoking status, pack years of smoking, and alcohol intake. In analyses stratified by natural hair color, models were not further adjusted for natural hair color. Included participants whose natural hair color was red, blond, and light brown. Cumulative dose of permanent hair dye use was calculated by multiplying average frequency of use (times per year) by duration of use (years).

*Not including basal cell carcinoma and cutaneous squamous cell carcinoma.

tP value for trend was calculated by using the mid-point of each category of cumulative dose in times.

$\ddagger P$ value for trend was calculated by using cumulative dose in times as continuous variable.

§Models were additionally adjusted for childhood reaction to sun, lifetime blistering sunburns, number of moles on arms, and cumulative ultraviolet flux since baseline.

IModels were additionally adjusted for menopausal status, postmenopausal hormone use, oral contraceptive use, adolescent body size, age at menarche, age at first birth, parity, breastfeeding,

first degree family history of breast cancer, history of benign breast disease, and current mammography use.

**Hormone receptor status was not available for all the breast cancer cases.

††Models were additionally adjusted for menopausal status, postmenopausal hormone use, age at menarche, oral contraceptive use, and parity.

¥¥Models were additionally adjusted for physical activity, menopausal status, postmenopausal hormone use, family history of colorectal cancer, history of diabetes mellitus, screening

colonoscopy or sigmoidoscopy in the previous two years, regular use of aspirin, regular use of non-aspirin non-steroidal anti-inflammatory drugs, multivitamin use, total calorie intake, red or processed meat intake, and intake of fiber, folate, calcium, and vitamin D.

$\S \S M o d e l s$ were additionally adjusted for total fluid intake.

१९Models were additionally adjusted for regular use of aspirin.

${ }_{\star \star \star \star}$ Models were additionally adjusted for physical activity, menopausal status, postmenopausal hormone use, parity, regular use of aspirin, regular use of non-aspirin non-steroidal anti-

inflammatory drugs, multivitamin use, total calories intake, history of hypertension, history of hypercholesterolemia, and history of diabetes mellitus. 
squamous cell carcinoma, melanoma, ovarian cancer, colorectal cancer, kidney cancer, lung cancer, and brain cancer, but it found a slightly increased risk of basal cell carcinoma. Larger cumulative dose was also not associated with higher risk of most of these specific cancer subtypes in our analyses, except for breast cancer and ovarian cancer. Our results among US women conflict with previous reports on brain cancer and lung cancer but are consistent with studies on basal cell carcinoma, ovarian cancer, and melanoma. ${ }^{60-47}$ The possibility of a spurious finding for ovarian cancer cannot be ruled out given the sensitivity analyses. Our study examined permanent hair dye use in relation to risk of cutaneous squamous cell carcinoma, colorectal cancer, and kidney cancer. We found no positive association between personal use of permanent hair dyes and cancer related death, which confirms the findings in previous reports. ${ }^{2248}$

We observed potentially lower risks of lung cancer, brain cancer, and chronic lymphocytic leukemia or small lymphocytic lymphoma among ever users of permanent hair dyes and those who used larger cumulative doses. These observations are difficult to account for and warrant re-evaluation in other investigations. We encourage caution when interpreting these findings owing to uncertainty about their biological plausibility.

We observed mixed findings for several endpoints when examining non-users versus ever users and cumulative dose of hair dyes in analyses stratified by natural hair color. One plausible assumption (among several) linking natural hair color with the color of hair dyes used could be that, especially in the birth cohorts specific to the Nurses' Health Study, women tended to use hair dye products with the same color as their natural hair color. We do not have data to directly assess this assumption or other plausible assumptions. However, if this assumption holds, women with naturally dark hair who presumably used dark colored permanent hair dyes experienced an increased risk of Hodgkin lymphoma. Possible explanations could be that shades of permanent hair dyes are associated with the concentration of ingredients, with darker colors having higher concentrations. However, we also reported that women with naturally light colored hair who presumably dyed their hair using light colored permanent hair dyes had a higher risk of basal cell carcinoma, which remains difficult to explain. Until these findings can be confirmed in other large populations and mechanisms elucidated, they require cautious interpretation. More research is needed to identify the specific chemical constituents that might be contributing to these increased risks.

\section{Strengths and limitations of study}

Our study had several noteworthy strengths. Firstly, it was a large study (comprising over 117000 eligible participants, with more than 47000 incident cancers and over 4800 cancer related deaths documented during 36 years of follow-up), and the prospective design and high follow-up rates (exceeding 90\% in most questionnaire cycles, including the cycles when information on hair dye exposure was assessed) minimized the potential for bias. Secondly, we had validated, time varying information on a wide spectrum of known or plausible confounders, which allowed relatively rigorous control for confounding throughout follow-up for every specific cancer, even though our exposure information was not updated after the first six years. ${ }^{19-26}$ Thirdly, we measured diverse major domains of exposure (overall status, duration and frequency of use, cumulative dose, age at first use, and time since first use), presenting an important advantage which has not been addressed by most previous studies. ${ }^{9}$ Although a study validating measurements of hair dye exposure and certain confounding variables has not been performed (eg, body mass index at age 18, childhood reaction to sun, which involved participants recalling information from long before the baseline), we have confidence in the reliability of our exposure assessments and in the retrospectively assessed variables because a wide range of measurements on anthropometrics, lifestyle, diet, and medical history have previously been shown to be valid in the Nurses' Health Study cohort. ${ }^{19-26}$ Fourthly, the availability of detailed medical records and pathology reports enabled us to examine heterogeneity across major cancer subtypes, including some individual lymphoid malignancies and several individual breast cancer subtypes according to hormone receptor status. Finally, the high homogeneity of our study participants (all trained health professionals) minimized underreporting or misreporting of cancer diagnoses before final confirmation by study investigators through medical record confirmation and cancer registry linkages, further ensuring high quality data, minimal socioeconomic confounding, and enhanced internal validity.

This study has several limitations. Firstly, our cohort was not randomly sampled from US women, but enrolled only healthcare professionals and more than $96 \%$ of the women had European ancestry. Therefore, although racial or ethnical disparities in the association between personal permanent hair dye use and risk of certain cancers (eg, breast cancer ${ }^{37}{ }^{38}$ ) have been suggested in previous studies, we were not able to investigate heterogeneity across race or ethnicity in cancer risk and mortality in this cohort, limiting the generalizability of our findings. Additionally, compared with the general population, nurses might be more adept at taking precautions while applying hair dyes (eg, following directions, using gloves, keeping track of time, rinsing the scalp thoroughly with water after use), which could limit the generalizability of our findings. Secondly, although we performed extensive multivariate analyses to address confounding, the possibility of residual unmeasured confounding remains. For example, we lacked information on exposure to oncogenic infections, family history of hematopoietic cancer, and exposure to pesticides and other putative environmental risk factors in analyses of hematopoietic cancers, or information on skin tone in 
analyses of cutaneous cancers. Other examples include the lack of information on use of other hair dye and hair straightening products in addition to permanent hair dyes. Women who use hair dye products might also use other cosmetics more commonly, which could also contain a wide spectrum of effective chemicals $^{39}$; confounding from this exposure could not be addressed. Moreover, information about the localization of cutaneous cancers was also unavailable.

The third limitation of our study pertains to potential misclassification of hair dye use. Specifically, owing to a lack of questions on participants' history of nonpermanent hair dye use, some users of non-permanent hair dyes might have misunderstood and inadvertently misclassified themselves as permanent hair dye users. ${ }^{17} 49$ Further, given that exposure assessments ceased relatively early during cohort follow-up, exposure domains might be underestimated, which could bias our results towards the null. Moreover, given the potential for non-differential recall, the baseline exposure assessment might have been more misclassified than subsequent assessments because of the longer time frame. Another potential concern is whether exposure measurements were less relevant 30 years later than they were in the shorter term. However, it is relatively rare that effects of genotoxic agents are immediate. A latency of even decades might exist before the effect of genotoxic agents could be observed. ${ }^{50}$ By restricting follow-up to the first 10 and 20 years of follow-up, we reported no material variation of the observed associations under this assumption for most of the endpoints. Finally, the potential of chance findings owing to multiple comparisons merits consideration. However, considering that we used only five distinct exposure scales in our analyses, all of which related to hair dye use and were complementary to each other because they allowed different aspects of causality to be assessed, we were conservative in our adjustments for multiple comparisons.

Other challenges relating to human evidence of the carcinogenicity of permanent hair dye use should be mentioned. Firstly, our data collection on permanent hair dyes might not exactly represent exposure today or in the past 10 years. Hair dyes might contain hundreds of chemicals, ${ }^{247}$ with ingredients that have changed over time. ${ }^{1-47}$ Whereas there was little innovation in the components of permanent hair dyes between the 1930s and 1970s, ${ }^{1}$ the cosmetic industry has made several changes in the composition of permanent hair dyes since the 1980s. These changes were in response to the US Food and Drug Administration warning on the safety of permanent hair dyes that contain 4-methoxym-phenylenediamine (2,4-diaminoanisole), or its

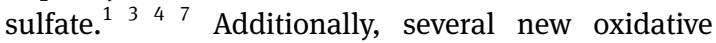
substances were introduced during the same period. ${ }^{1}$ In this study, we could not conduct a stratified analysis of permanent hair dye use before or after $1980^{7}$ because not enough women reported first use of permanent hair dye after 1980 (1890/117 200). This lack of use could be because our study participants are all health professionals, which might have made them more sensitive than the general population to the cautionary label that appeared on permanent hair dye packaging from 1980 onwards. ${ }^{35}$ However, considering that most of the frequently used modern permanent hair dye ingredients (including para phenylenediamine, resorcinol, 2,5-diaminotoluene, para and meta aminophenol, 4-amino-2-hydroxytoluene, 4-amino-meta-cresol, and 2-methyl-5hydroxyethylaminophenol) have been on the market since the 1930 s, $^{1}$ our findings should still be relevant to current day exposure regardless of type and shade of color (they are regulated according to their ingredients regardless of the shade ${ }^{4}$ ) and therefore have public health implications.

Secondly, the carcinogenic potential of dark colored permanent hair dyes are of greatest concern. ${ }^{1} 27$ Permanent hair dyes consist of dye intermediates (aromatic amines) and couplers, which can react with each other to form pigment molecules. ${ }^{12}$ The shades of color are approximately proportional to the concentration of ingredients (a clear estimate cannot be made because of the complexity of ingredients)darker hair dyes tend to contain higher concentrations of ingredients, whereas lighter shades contain lower concentrations. ${ }^{12}$ Additionally, lead acetate based dark colored products can still be found on the international market. ${ }^{14}$ Previous studies have particularly noted a potential increase in cancer risk for users of dark colored permanent hair dyes. ${ }^{17}$ However, in our study, we lacked information on the color of permanent hair dyes used, instead conducting analyses stratified by natural hair color to explore the question of heterogeneous effects only indirectly (presuming that participants would use dyes of a similar color to their natural hair color). Thirdly, the reported increase in using natural (eg, henna or its pure dye ingredient) or direct (semipermanent or temporary) dye in combination with permanent hair dye should be noted, ${ }^{1}$ and their safety warrants further investigations. Fourthly, attention should be paid to differences relating to permanent hair dye use in personal and occupational exposure settings. Although the chemical composition of hair dye products for occupational use is similar to that for home use, the cumulative dose of dermal and airborne exposure for hairdressers or beauticians could be higher (prolonged time with higher frequency) than that of consumers. ${ }^{137}$

Finally, legislation and regulation of ingredients in hair dye formulations differ by country, adding further complexity. ${ }^{1}$ In the US, permanent hair dyes do not require premarket approval by the US Food and Drug Administration ${ }^{3}{ }^{4}$; manufacturers are responsible for the safety of ingredients. ${ }^{7}$ However, the US Food and Drug Administration continues to monitor safety concerns about these products. ${ }^{3} 4$ Additionally, Europe, but not the US, has banned a number of individual hair dye ingredients that were considered putatively carcinogenic during the $1980 \mathrm{~s}$ and 2000s. ${ }^{1}$ The most restrictive regulation of hair dyes exists in Japan where cosmetic products are considered equivalent to drugs ${ }^{.1}$ 


\section{Conclusion and public health implications}

This prospective cohort study among mostly white US women offers some reassurance against concerns that personal use of permanent hair dyes might be associated with increased cancer risk or mortality. However, we did find a positive association for risk of some cancers, including basal cell carcinoma, breast cancer (estrogen receptor negative, progesterone receptor negative, hormone receptor negative) and ovarian cancer. Additionally, mixed results were found in analyses stratified by natural hair color for some endpoints (increased risk of Hodgkin lymphoma was observed only among women with naturally dark hair; higher risk of basal cell carcinoma was observed specifically among women with naturally light hair). The generalizability of current findings is limited to white US women and might not extend to other populations. Our findings warrant further prospective validation in diverse populations and nations, various susceptibility genotypes (eg, N-acetytransferases, NAT1 or NAT2), cancers of various genotypes and molecular genetic phenotypes, different exposure settings (personal use $v$ occupational exposure), different timings, and colors of permanent hair dyes used (dark $v$ light colored). Additionally, exposure assessments should be more refined and interpreted in the light of the totality of evidence.

\section{AUTHOR AFFILIATIONS \\ ${ }^{1}$ Channing Division of Network Medicine, Department of Medicine, Brigham and Women's Hospital and Harvard Medical School, Boston, MA, USA \\ ${ }^{2}$ Department of Medical Oncology, Dana-Farber Cancer Institute and Harvard Medical School, Boston, MA, USA \\ ${ }^{3}$ Department of Epidemiology, Harvard TH Chan School of Public Health, Boston, MA, USA \\ ${ }^{4}$ Department of Epidemiology, Richard M Fairbanks School of Public Health, Indiana University, Indianapolis, IN, USA \\ ${ }^{5}$ Melvin and Bren Simon Cancer Center, Indiana University, Indianapolis, IN, USA}

${ }^{6}$ Department of Nutrition, Harvard T H Chan School of Public Health, Boston, MA, USA

${ }^{7}$ Department of Environmental Health, Harvard T H Chan School of Public Health, Boston, MA, USA

${ }^{8}$ Department of Biostatistics, Harvard T H Chan School of Public Health, Boston, MA, USA

${ }^{9}$ Department of Epidemiology, Center for Public Health, Medical University of Vienna, Vienna, Austria

The authors thank all participants and staff of the Nurses' Health Study for their contributions to this research. We are grateful for help from the following state cancer registries: Alabama, Arizona, Arkansas, California, Colorado, Connecticut, Delaware, Florida, Georgia, Idaho, Illinois, Indiana, Iowa, Kentucky, Louisiana, Maine, Maryland, Massachusetts, Michigan, Nebraska, New Hampshire, New Jersey, New York, North Carolina, North Dakota, Ohio, Oklahoma, Oregon, Pennsylvania, Rhode Island, South Carolina, Tennessee, Texas, Virginia, Washington, and Wyoming.

Contributors: ESS and YZ were involved in the study concept and design. YZ performed statistical analysis. YZ interpreted data and drafted the manuscript. All authors participated in critical revision of the manuscript for important intellectual content. BMB, JH, ELG, FES, MJS, and BAR contributed to administrative, technical, and material support. ESS obtained funding. YZ and ESS had full access to all the data in the study and take responsibility for the integrity of the data and the accuracy of the data analysis. All authors approved the final version of this paper and the authorship list. YZ and ESS are the guarantors. The corresponding author attests that all listed authors meet authorship criteria and that no others meeting the criteria have been omitted.
Funding: This research was supported by grant $\mathrm{R0} 1 \mathrm{OH} 009803$ from the Centers for Disease Control and Prevention and the National Institute for Occupational Safety and Health. The Nurses' Health Study was supported by grant UM1 CA186107, UM1 CA176726, and P01 CA87969 from the National Cancer Institute. The funding sources played no role in the study design, data collection, data analysis, and interpretation of results, or the decisions made in preparation and submission of the article.

Competing interests: All authors have completed the ICMJE uniform disclosure form at www.icmje.org/coi_disclosure.pdf and declare: support from the Centers for Disease Control and Prevention and the National Institute for Occupational Safety and Health for the submitted work; no financial relationships with any organizations that might have an interest in the submitted work in the previous three years; no other relationships or activities that could appear to have influenced the submitted work.

Ethical approval: The study protocol was approved by the institutional review board at Brigham and Women's Hospital (1999P-011114), and those of participating registries as required. Consent from participants was indicated by the completion and return of the questionnaires.

Data sharing: Data, the statistical code, questionnaires, and technical processes are available from the corresponding author at eva.schernhammer@channing.harvard.edu.

The lead author (the manuscript's guarantor) affirms that the manuscript is an honest, accurate, and transparent account of the study being reported; that no important aspects of the study have been omitted; and that any discrepancies from the study as planned (and, if relevant, registered) have been explained.

Dissemination to participants and related patient and public communities: We plan to disseminate the results to study participants.

This is an Open Access article distributed in accordance with the Creative Commons Attribution Non Commercial (CC BY-NC 4.0) license, which permits others to distribute, remix, adapt, build upon this work non-commercially, and license their derivative works on different terms, provided the original work is properly cited and the use is noncommercial. See: http://creativecommons.org/licenses/by-nc/4.0/.

1 IARC Working Group on the Evaluation of Carcinogenic Risk to Humans. Some aromatic amines, organic dyes, and related exposures. IARC monographs on the evaluation of carcinogenic risks to humans. Volume 99. Lyon, 2010.

2 National Cancer Institute. Hair dyes and cancer risk. 2016 https:// www.cancer.gov/about-cancer/causes-prevention/risk/myths/hairdyes-fact-sheet.

3 IARC Working Group on the Evaluation of Carcinogenic Risk to Humans. IARC monographs on the evaluation of carcinogenic risks to humans. Occupational exposures of hairdressers and barbers and personal use of hair colourants; some hair dyes, cosmetic colourants, industrial dyestuffs and aromatic amines. Volume 57. Lyon. 1993.

4 The U.S. Food and Drug Administration. Hair dyes. 2019 https://www. fda.gov/cosmetics/cosmetic-products/hair-dyes.

5 Gunby P. FDA's hands somewhat tied on hair dye-cancer link. IAMA 1979:242:2525. doi:10.1001/jama.1979.03300230007006

6 Takkouche B, Etminan M, Montes-Martínez A. Personal use of hair dyes and risk of cancer: a meta-analysis. JAMA 2005;293:2516-25. doi:10.1001/jama.293.20.2516

7 American Cancer Society. Hair dyes. 2019 https://www.cancer.org/ cancer/cancer-causes/hair-dyes.html.

8 American Cancer Society. Known and probable human carcinogens. 2019 https://www.cancer.org/cancer/cancer-causes/general-info/ known-and-probable-human-carcinogens.html.

9 Zahm SH, Fraumeni JFJr. Hair dye use and non-Hodgkin lymphoma. JAMA 2005:294:1205, author reply 1205. doi:10.1001/ jama.294.10.1205-a

10 Turati F, Pelucchi C, Galeone C, Decarli A, La Vecchia C. Personal hair dye use and bladder cancer: a meta-analysis. Ann Epidemiol 2014;24:151-9. doi:10.1016/j.annepidem.2013.11.003

11 Gera R, Mokbel R, Igor I, Mokbel K. Does the use of hair dyes increase the risk of developing breast cancer? A meta-analysis and review of the literature. Anticancer Res 2018;38:707-16. doi:10.21873/ anticanres.12276

12 Towle KM, Grespin ME, Monnot AD. Personal use of hair dyes and risk of leukemia: a systematic literature review and meta-analysis. Cancer Med 2017;6:2471-86. doi:10.1002/cam4.1162

13 Belanger CF, Hennekens CH, Rosner B, Speizer FE. The Nurses' Health Study. Am J Nurs 1978;78:1039-40.

14 Belanger C, Speizer FE, Hennekens CH, Rosner B, Willett W, Bain C. The Nurses' Health Study: current findings. Am J Nurs 1980;80:1333. doi:10.1097/00000446-198007000-00024 
15 Colditz GA, Manson JE, Hankinson SE. The Nurses' Health Study: 20-year contribution to the understanding of health among women. J Womens Health 1997;6:49-62. doi:10.1089/jwh.1997.6.49

16 Colditz GA, Hankinson SE. The Nurses' Health Study: lifestyle and health among women. Nat Rev Cancer 2005;5:388-96. doi:10.1038/nrc1608

17 Grodstein F, Hennekens CH, Colditz GA, Hunter DJ, Stampfer MJ. A prospective study of permanent hair dye use and hematopoietic cancer. / Natl Cancer Inst 1994;86:1466-70. doi:10.1093/ jnci/86.19.1466

18 Wu S, Li WQ, Cho E, Harris JE, Speizer F, Qureshi AA. Use of permanent hair dyes and risk of vitiligo in women. Pigment Cell Melanoma Res 2015;28:744-6. doi:10.1111/pcmr.12402

19 Wolf AM, Hunter DJ, Colditz GA, et al. Reproducibility and validity of a self-administered physical activity questionnaire. Int J Epidemiol 1994:23:991-9. doi:10.1093/ije/23.5.991

20 Rimm EB, Stampfer MJ, Colditz GA, Chute CG, Litin LB, Willett WC Validity of self-reported waist and hip circumferences in men and women. Epidemiology 1990;1:466-73. doi:10.1097/00001648 199011000-00009

21 Feskanich D, Rimm EB, Giovannucci EL, et al. Reproducibility and validity of food intake measurements from a semiquantitative food frequency questionnaire. J Am Diet Assoc 1993;93:790-6. doi:10.1016/0002-8223(93)91754-E

22 Altekruse SF, Henley SJ, Thun MJ. Deaths from hematopoietic and other cancers in relation to permanent hair dye use in a large prospective study (United States). Cancer Causes Control 1999;10:617-25. doi:10.1023/A:1008926027805

23 Colditz GA, Martin P, Stampfer MJ, et al. Validation of questionnaire information on risk factors and disease outcomes in a prospective cohort study of women. Am J Epidemiol 1986;123:894-900. doi:10.1093/oxfordjournals.aje.a114319

24 Colditz GA, Stampfer MJ, Willett WC, et al. Reproducibility and validity of self-reported menopausal status in a prospective cohort study. Am J Epidemiol 1987;126:319-25. doi:10.1093/aje/126.2.319

25 Stampfer MJ, Willett WC, Speizer FE, et al. Test of the National Death Index. Am J Epidemiol 1984;119:837-9. doi:10.1093/ oxfordjournals.aje.a113804

26 Rich-Edwards JW, Corsano KA, Stampfer MJ. Test of the National Death Index and Equifax Nationwide Death Search. Am J Epidemiol 1994;140:1016-9. doi:10.1093/oxfordjournals.aje. a117191

27 Wei EX, Li X, Nan H. Having a first-degree relative with melanoma increases lifetime risk of melanoma, squamous cell carcinoma, and basal cell carcinoma. J Am Acad Dermatol 2019;81:489-99. doi:10.1016/i.jaad.2019.04.044

28 VoPham T, Hart JE, Bertrand KA, Sun Z, Tamimi RM, Laden F. Spatiotemporal exposure modeling of ambient erythemal ultraviolet radiation. Environ Health 2016;15:111. doi:10.1186/s12940-0160197-x

29 Lebwohl B, Cao Y, Zong G, et al. Long term gluten consumption in adults without celiac disease and risk of coronary heart disease: prospective cohort study. BMJ 2017;357:j1892. doi:10.1136/bmj. j1892

30 Veronese N, Li Y, Manson JE, Willett WC, Fontana L, Hu FB. Combined associations of body weight and lifestyle factors with all cause and cause specific mortality in men and women: prospective cohort study. BMJ 2016;355:i5855. doi:10.1136/bmj.i5855

31 Bertoia ML, Rimm EB, Mukamal KJ, Hu FB, Willett WC, Cassidy A. Dietary flavonoid intake and weight maintenance: three prospective cohorts of 124,086 US men and women followed for up to 24 years. BMJ 2016;352:i17. doi:10.1136/bmj.i17

32 Tabung FK, Liu L, Wang W, et al. Association of dietary inflammatory potential with colorectal cancer risk in men and women. JAMA Oncol 2018;4:366-73. doi:10.1001/jamaoncol.2017.4844
33 Tobias DK, Stuart JJ, Li S, et al. Association of history of gestational diabetes with long-term cardiovascular disease risk in a large prospective cohort of US women. JAMA Intern Med 2017;177:1735 42. doi:10.1001/jamainternmed.2017.2790

34 Anagnostopoulos I, Hansmann ML, Franssila K, et al. European Task Force on Lymphoma project on lymphocyte predominance Hodgkin disease: histologic and immunohistologic analysis of submitted cases reveals 2 types of Hodgkin disease with a nodular growth pattern and abundant lymphocytes. Blood 2000;96:1889-99.

$35 \mathrm{Li} \mathrm{Cl}$, Malone KE, Daling JR. Differences in breast cancer hormone receptor status and histology by race and ethnicity among women 50 years of age and older. Cancer Epidemiol Biomarkers Prev 2002:11:601-7.

36 Carey LA, Perou CM, Livasy CA, et al. Race, breast cancer subtypes, and survival in the Carolina Breast Cancer Study. JAMA 2006:295:2492-502. doi:10.1001/jama.295.21.2492

37 Eberle CE, Sandler DP, Taylor KW, White AJ. Hair dye and chemical straightener use and breast cancer risk in a large US population of black and white women. Int / Cancer 2020;147:383-91. doi:10.1002/ijc.32738

38 Fillon M. New study links hair chemicals to breast cancer. CA Cancer Clin 2020;70:141-2. doi:10.3322/caac.21602

39 Alipour S. Comments on: Hair dye and chemical straightener use and breast cancer risk in a large US population of black and white women. Int J Cancer 2020;146:2651. doi:10.1002/ijc.32852

40 Bluhm EC, Zahm SH, Fine HA, et al. Personal hair dye use and risks of glioma, meningioma, and acoustic neuroma among adults. Am J Epidemiol 2007;165:63-71. doi:10.1093/aje/kwk002

41 Heineman EF, Ward MH, McComb RD, Weisenburger DD, Zahm SH. Hair dyes and risk of glioma among Nebraska women. Cancer Causes Control 2005;16:857-64. doi:10.1007/s10552-005-3204-z

42 Feizy V, Toosi S. Relation of basal cell carcinoma to hair dye use. J Am Acad Dermatol 2009.61.532-3. doi.10.1016/j.jaad 2009.01.040

43 Czene K, Tiikkaja S, Hemminki K. Cancer risks in hairdressers: assessment of carcinogenicity of hair dyes and gels. Int J Cancer 2003;105:108-12. doi:10.1002/ijc.11040

44 Tai SY, Hsieh HM, Huang SP, Wu MT. Hair dye use, regular exercise, and the risk and prognosis of prostate cancer: multicenter case-control and case-only studies. BMC Cancer 2016;16:242. doi:10.1186/s12885-016-2280-7

45 McCall EE, Olshan AF, Daniels JL. Maternal hair dye use and risk of neuroblastoma in offspring. Cancer Causes Control 2005;16:743-8. doi:10.1007/s10552-005-1229-y

46 Parodi S, Merlo DF, Ranucci A, et al, SETIL Working Group. Risk of neuroblastoma, maternal characteristics and perinatal exposures: the SETIL study. Cancer Epidemiol 2014;38:686-94. doi:10.1016/j. canep.2014.09.007

47 Holly EA, Bracci PM, Hong MK, Mueller BA, Preston-Martin S. West Coast study of childhood brain tumours and maternal use of haircolouring products. Paediatr Perinat Epidemiol 2002;16:226-35. doi:10.1046/j.1365-3016.2002.00420.x

48 Thun MJ, Altekruse SF, Namboodiri MM, Calle EE, Myers DG, Heath CWJr. Hair dye use and risk of fatal cancers in U.S. women. J Nat Cancer Inst 1994;86:210-5. doi:10.1093/jnci/86.3.210

49 Koenig KL, Pasternack BS, Shore RE, Strax P. Hair dye use and breast cancer: a case-control study among screening participants. Am J Epidemiol 1991;133:985-95. doi:10.1093/oxfordjournals.aje. a115818

50 Smith AH, Marshall G, Roh T, Ferreccio C, Liaw J, Steinmaus C. Lung, bladder, and kidney cancer mortality 40 years after arsenic exposure reduction. J Natl Cancer Inst 2018;110:241-9. doi:10.1093/jnci/ djx201

Web appendix: Supplementary material 